\title{
Neurotrophin-3 influences the number and the laminar fate of cortical pro- genitors in the developing cerebral cortex of mice through the MEK/ERK1/2 signaling pathway
}

\author{
Masanari Ohtsuka , Hitomi Soumiya, Masami Hanai, Shoei Furukawa, and Hidefumi Fukumitsu \\ Laboratory of Molecular Biology, Department of Biofunctional Analysis, Gifu Pharmaceutical University, Daigakunishi 1-25-4, Gifu \\ 501-1196, Japan
}

(Received 25 July 2013; and accepted 15 August 2013)

\begin{abstract}
The laminar formation in the developing cerebral cortex requires precisely regulated generation of phenotype-specific neurons. To determine whether neurotrophin-3 (NT3) is involved in this formation, we investigated the effects of NT3 administration in the telencephalic ventricular space on 13.5-day-old mouse embryos. NT3 increased the number of newly generated neurons and altered the neuronal phenotypes in the position and the transcription factors-expression profiles; the neuronal phenotypes originally committed for layer IV neurons were altered toward for layers II/III neurons. The former effects were observed when the parent progenitor cells were exposed to NT3 in the G1- to S-phase, whereas the latter effects were observed with exposure in the G1-phase. In addition, in vitro experiments revealed that the laminar fate alteration by NT3 was observed in the dissociated primary culture of cortical progenitors and the NT3 actions were suppressed by cotreatment with the MEK/ERK inhibitor. These observations suggest that NT3 is involved in the laminar formation of the developing cerebral cortex through the intercellular MEK/ERK pathway.
\end{abstract}

The mammalian cerebral cortex is organized into six layers, with each layer containing neurons with similar morphology, functions, gene expression profiles, and projection patterns $(10,11)$. These layer-specific neuronal phenotypes are generated from the common cortical neural progenitors in the ventricular zone (VZ), and subsequently, the postmitotic neurons migrate to their destinations within the cortical plate (CP) $(1,29)$. Several studies have revealed the involvement of intrinsic factors, such as transcription factors, and cell cycle regulators in this process $(4,5)$. Growth factors and neurotrophic factors environmentally supplied by the cerebral cortex are believed to regulate proliferation and determine

Address correspondence to: Dr. Hidefumi Fukumitsu, Laboratory of Molecular Biology, Department of Biofunctional Analysis, Gifu Pharmaceutical University, Daigakunishi 1-25-4, Gifu 501-1196, Japan

Tel: +81-58-230-8100, Fax: +81-58-230-8105

E-mail: hfukumi@gifu-pu.ac.jp neuronal differentiation (16).

Previous transplantation experiments (20) suggest that environmental factors existing in the older host cortical tissue influence the laminar fate of cortical progenitors prepared from younger embryo donors. These progenitors can generate upper layer neurons before entering the S-phase, whereas the progenitors that have already passed through the S-phase are committed to their original fate to generate deep layer neurons. Our previous studies demonstrated that brain-derived neurotrophic factor (BDNF) is one such environmental factor. Administration of BDNF or function-blocking antibodies can alter the laminar-specific properties of cortical neurons determined for layer IV to the neurons located in deeper or upper cortical layers, respectively. However, BDNF could influence the progenitors when they were in the S-phase, but not in the G1-phase (8).

On the other hand, recent evidences increasingly

\footnotetext{
${ }^{\#}$ These authors contributed equally to this work.
} 
demonstrate that molecules regulating the G1-phase progression in cortical progenitors directly influence the number of neurons and their laminar-specific properties $(27,30)$. These findings suggest that some groups of environmental factors may act on progenitors in their G1-phase and alter both the number and the laminar-specific properties of their daughter neurons. We believe one of candidate environmental factors that may exhibit such characteristics is neurotrophin-3 (NT3) because of the following reasons. First, NT3 and its high affinity receptor, TrkC, are expressed in $\mathrm{CP}$ neurons and in progenitors proliferating in the subventricular zone (SVZ)/VZ $(9,17)$. Second, NT3 facilitates the cell-cycle exit and neural differentiation of the cortical progenitors both in vivo and in vitro $(19,25)$. Third, NT3, but not BDNF, activates extracellular signal-regulated kinase (ERK)1/2 and ERK5 in the SVZ/VZ (25). Finally, ERK1/2 regulates cyclin D1 and $\mathrm{p} 27^{\mathrm{Kip} 1}$, two potent G1 cell cycle regulators $(12,28)$.

In the present study, we investigated the influence of NT3 on the laminar fate of cortical progenitors using an in utero microinjection technique. Our results demonstrated that NT3 altered the number of cortical neurons and their laminar fate by acting on the parent progenitors through MEK/ERK1/2 pathway in two distinct time windows during the G1phase.

\section{MATERIALS AND METHODS}

Animals. All experiments were approved by the Animal Research Committee of Gifu Pharmaceutical University in Gifu, Japan and were carried out in accordance with the National Institutes of Health guidelines on animal care. All efforts were made to minimize the number of animals used and their suffering.

Pregnant ddY mice were purchased from Japan SLC (Shizuoka, Japan). The surgical procedures performed on the mice are described in a previous report (25). In brief, pregnant mice carrying 13.5-dayold embryos (E13.5) were deeply anesthetized with sodium pentobarbital injected intraperitoneally (i.p., $30 \mu \mathrm{g} / \mathrm{g}$ ), and the uterine horns were exposed. One microliter of phosphate-buffered saline (PBS) containing NT3 (3 $\mu \mathrm{g}$; purchased from Alamone Laboratories, Jerusalem, Israel) was then injected into the ventricular space of each embryo with a microinjector equipped with a glass microcapillary (GD-1; Narishige, Tokyo, Japan). The uterus was then returned to the abdominal cavity to allow normal development of the embryos. Most of the pregnant mice delivered their pups normally.

5-bromo-2'-deoxyuridine injection schedules. Pregnant mice were injected i.p. with 5-bromo-2'-deoxyuridine (BrdU, $50 \mu \mathrm{g} / \mathrm{g}$ body weight) (Sigma-Aldrich Co., St. Louis, MO) in sterile PBS. On postnatal day 6 (P6), the offspring were killed with an overdose of diethyl ether, and their brains were collected ( $n=4-5$ pups in each group from the 2 litters). The cortical tissues were processed, and the distributions of the BrdU-positive cells (cells ${ }^{\mathrm{BrdU}+}$ ) were analyzed as described below in the Quantitative studies on cells ${ }^{\mathrm{Brd}+}$ subsection.

Tissue preparation. The mice were processed and analyzed as previously described (25). In brief, postnatal brains were removed after perfusion with $4 \%$ paraformaldehyde solution through the heart and were postfixed overnight. The brains were soaked in PBS containing $20 \%$ sucrose (w/v) and were frozen in embedding compound (Sakura Finetechnical Co., Ltd., Tokyo, Japan). Serial coronal sections $(20 \mu \mathrm{m}$ thick) were prepared with a cryostat (model CM 1800; Leica Microsystems GmbH, Wetzlar, Germany), attached to adhesive-coated slides (Matsunami Glass Ind., Ltd., Osaka, Japan), and then dried before being subjected to immunohistochemical studies.

Immunostaining. Immunohistochemical analyses were performed using previously described procedures (25). Primary antibodies used were raised against the following proteins: brain-specific homeobox/POU domain protein 1 (Brn1, also known as Pou3f3; 1: 100; Santa Cruz Biotechnology, Inc., Santa Cruz, CA), the ortholog of the drosophila cut gene (Cux1; 1 : 500; Santa Cruz), Ctip2 (COUP-TF1 (chicken ovalbumin upstream promoter transcription factor)-interacting protein 2; $1: 500$; Abcam, Cambridge, UK), Tbr1 (T-box brain 1; 1: 1000; Chemicon/Millipore, Billerica, MA), Tle4 (transducin-like enhancer of split 4; $1: 500$; Abcam) and Foxp2 (Forkhead box p2; 1: 100; Santa Cruz). These primary antibodies were visualized with goat antimouse IgG, anti-rabbit IgG conjugated to Alexa 488 or 546 (1:1000; Life Technologies Co., Carlsbad, $\mathrm{CA})$, or donkey anti-goat IgG conjugated to Alexa 546 (1 : 1000; Life Technologies Co.); fluorescent signals were observed with a confocal laser microscope (Model LSM 510; Carl Zeiss, Inc., Jena, Germany). For detecting the cells ${ }^{\mathrm{BrdU}+}$, sections were treated with $2 \mathrm{~N} \mathrm{HCl}$ for $30 \mathrm{~min}$ at $37^{\circ} \mathrm{C}$ and $0.1 \%$ $(\mathrm{w} / \mathrm{v})$ trypsin in PBS to unmask BrdU before being reacted with anti-BrdU antibody (clone IU-4, $1: 5000$; 
Monosan, Uden, Netherlands). Fluorescent images were digitally converted to reversed monochrome with Photoshop (Adobe Systems Incorporated, San Jose, CA) if the sections revealed immunostaining with a single primary antibody.

Quantitative studies on cells ${ }^{\text {BrdU+ }}$. The distribution and quantification of cells ${ }^{\mathrm{BrdU}+}$ were analyzed by focusing on the area of the dorsomedial cerebral wall overlying the medial region of the lateral ventricle, which in the embryo corresponded to the primary somatosensory representation or the primary somatosensory cortex in the P6 mice [S1 barrel field in Figures 126-130 in the stereotaxic atlas] (26). The sample size for analysis in the P6 mice was $400 \mu \mathrm{m}$ in the mediolateral dimension and $500 \mu \mathrm{m}$ in the anteroposterior dimension. One series of every fourth sections was selected, and total five sections per brain were examined within the anteroposterior dimension. The cerebral cortex was evenly divided into 10 sectors having equal widths and heights along the ventricular lumen. The sectors were numbered in order from the ventricular surface outward. The cells ${ }^{\mathrm{BrdU}+}$ appearing in each sector were counted using the following criteria: 1) nuclei of cells $\mathrm{s}^{\mathrm{BrdU}+}$ located at boundaries between 2 sectors were assigned to the sector closest to the ventricle and 2) positive nuclei or cell bodies located on medial or lateral boundaries were all counted, even if the diameters were smaller than their maximal ones. In addition, endothelial cells were excluded from the count. This analysis was performed with $5-6$ brains from each group of the 2 litters.

Primary culture of cortical progenitor cells. Cortical progenitor cells were prepared from the telencephalon of 13.5-day-old ddY mouse embryos as previously described (15). In brief, dissected cortices were transferred to the culture medium (DMEMF12, Sigma-Aldrich) supplemented with insulin $(25 \mu \mathrm{g} / \mathrm{mL})$, apo-transferrin $(100 \mu \mathrm{g} / \mathrm{mL})$, progesterone $(20 \mathrm{nM})$, putrescine $(100 \mu \mathrm{M})$, and selenium $(30 \mathrm{nM})$, and then mechanically dissociated into single cells. The cells were seeded onto coverslips coated with poly-L-ornithine in 24-well culture plates with a density of $5 \times 10^{4}$ cells. After the attachment, cortical progenitor cells were administered BrdU $(10 \mu \mathrm{M}) 6 \mathrm{~h}$ after NT3 treatment $(100 \mathrm{ng} / \mathrm{mL})$. One hour after BrdU administration, culture medium was replaced with the same volume of fresh medium. Half of the medium was replaced with fresh medium every 3 days thereafter, and the cells were fixed with $4 \%$ paraformaldehyde on day 7 in vitro.
For inhibitor treatment, U0126 $(10 \mu \mathrm{M}$, SigmaAldrich) or LY294002 (50 $\mu \mathrm{M}$, Sigma-Aldrich) were administered 10 min before NT3 addition.

Quantitative RT-PCR. Quantitative RT-PCR was performed as previously described (7). In brief, total RNA was isolated from NT3- or vehicle-treated cerebral cortex using Trizol ${ }^{\circledR}$ Reagent (Life Technologies Co.). Total RNA ( $1 \mu \mathrm{g})$ with Superscript (Takara, Ohtsu, Japan) was used for the reverse-transcription reaction, according to the manufacturer's introductions. PCR was performed with $\mathrm{SYBR}^{\circledR}$ Premix Ex$\mathrm{Taq}^{\mathrm{TM}}$ (Takara) and analyzed with Thermal Cycler Device $^{\mathrm{TM}}$ Real-time System (Takara). The following primer sets were used: cyclin D1, forward 5'-AGA CCATCCGCAAGCATGCACA-3', reverse 5'-AGG TTCAGGCCTTGCATCGCA-3'; cyclin D2, forward, 5'-TTCGCAAGCTGCCCCAGCAAA-3', reverse 5'-GACGGCGGGTACATGGCAAAC-3'. As a control, glyceraldehyde-3-phosphate dehydrogenase (GAPDH) mRNA levels were quantified using similar procedures and were used to normalize the data using the following primers: forward 5'-ATG CATCCTGCACCACCAACTG-3' and reverse 5'ATCACGCCACAGCTTTCCAGAG-3'.

Statistical analyses. Data herein are presented as mean \pm SE. The statistical significance for differences between groups was assessed using Student's $t$-test, and the differences among multiple groups were assessed using one-way analyses of variance (ANOVAs) followed by Tukey's or Dunnett's post hoc tests.

\section{RESULTS}

NT3 affected the laminar distribution or the number of newly generated cortical neurons

To examine NT3 effects on the distribution of the newly generated cells, we administered BrdU to the pregnant mice bearing E13.5 embryos either $3 \mathrm{~h}$ or $6 \mathrm{~h}$ after NT3 administration. We then examined the distribution of the cells ${ }^{\mathrm{BdU}+}$ in the P6 with a confocal laser microscope (Fig. 1A). In the mouse cerebral cortex, most neurons complete their migration, and the cortical lamination is established by the first postnatal week $(2,13)$. In the vehicle-injected mice, the highest numbers of cells ${ }^{\mathrm{BrdU}+}$ were observed in sectors 6 and 7, which correspond to layer IV of the cerebral cortex (Fig. 1B, C). In the P6 cerebral cortex of mice treated with NT3 $6 \mathrm{~h}$ before the BrdU injection on E13.5, most cells $\mathrm{s}^{\mathrm{BrdU}+}$ were localized in sectors 7-9, which corresponds to layers II/III of the 
A

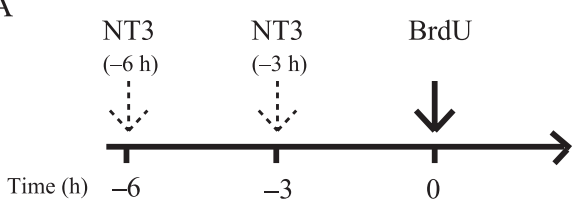

B

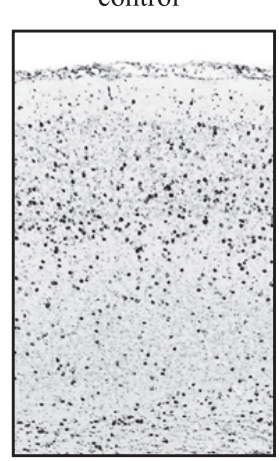

control

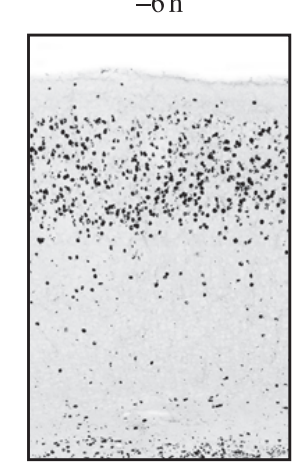

$-6 \mathrm{~h}$

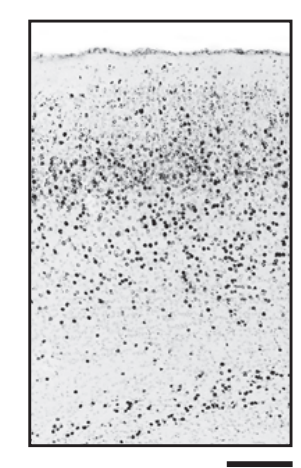

$\mathrm{C}$

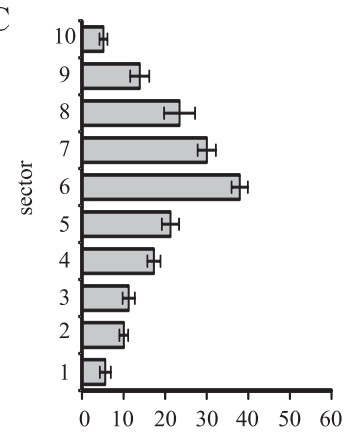

D

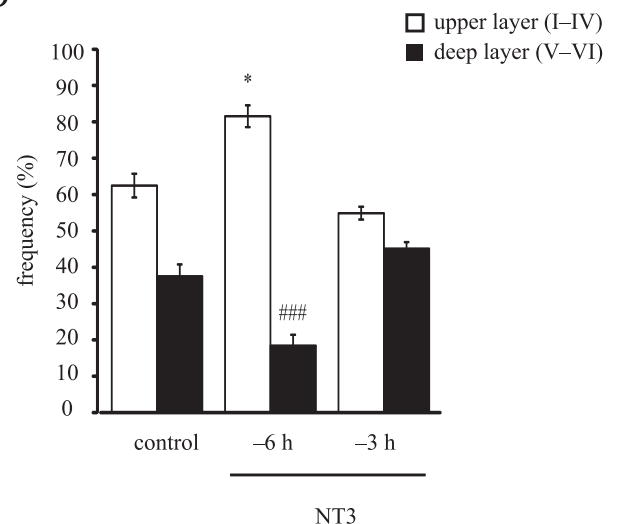

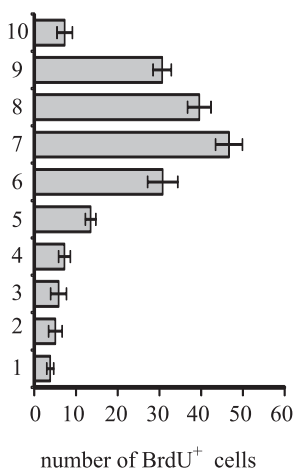

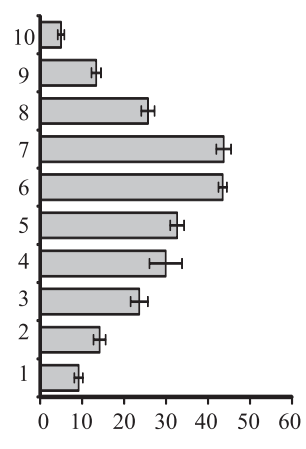

E

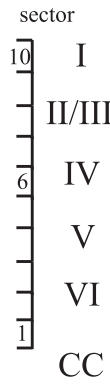

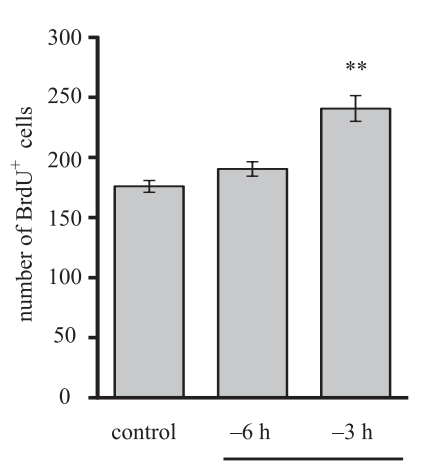

NT3

Fig. 1 Effects of NT3 on the number and the distribution of cells ${ }^{\text {BrdU+ }}$ in the postnatal day 6 (P6) cerebral cortex. A, Pregnant mice bearing E13.5 embryos received a single injection of BrdU $3 \mathrm{~h}$ or $6 \mathrm{~h}$ after ventricular administration of NT3 (3 $\mu \mathrm{g} /$ embryo), or vehicle. B, On the P6, brains were excised and processed for immunostaining. Scale bars of $200 \mu \mathrm{m}$. C, Distribution of the cells ${ }^{\text {BrdUt }}$ in the P6 cerebral cortex treated with vehicle (control), NT3 $(-6 \mathrm{~h},-3 \mathrm{~h})$ at E13.5. D, The ratio of cells $^{\mathrm{BrdU}+}$ in the upper layer and deep layers [ANOVA, Tukey's post hoc test, ${ }^{*} P<0.05$ (vs. control upper layer), \#\#\#P< 0.001 (vs. control deeper layer)]. E, The total number of cells ${ }^{\text {Brdut }}$ is expressed as the mean $\pm S E(n=5-6)$. An analysis of variance analysis (ANOVA) was used to examine differences in number of cells ${ }^{\mathrm{BrdU}+}$ between the NT3-treated cortex and the control cortex (Tukey's post hoc test, ${ }^{* *} P<0.01$ ). CC, corpus callosum. 
(Fig. 1B, C). Thus, for a substantial number of cells ${ }^{\mathrm{BrdU}+}$, NT3 altered the final destination to the upper cortical layers. Such distributional alterations of cells $^{\mathrm{BrdU+}}$ were observed in the P6 cerebral cortex of mice injected with BrdU $6 \mathrm{~h}$ but not $3 \mathrm{~h}$ after NT3 treatment on E13.5 (Fig. 1D). In other words, NT3 altered the final destination of the progenitors when they were in the cell cycle $6 \mathrm{~h}$ but not $3 \mathrm{~h}$ before BrdU incorporation. According to previous studies, the durations of G1-, S-, and G2/M-cell cycle phases for E13.5 cortical progenitors were 10.4, 3.3-3.8, and $2.0 \mathrm{~h}$, respectively (8). NT3 and BrdU are biologically active within $2 \mathrm{~h}(25)$ and $5 \mathrm{~h}$, respectively (31). Therefore, cells ${ }^{\mathrm{BrdU}+}$ were considered to be in the late G1/S-phase or in the G1-phase when NT3 was injected $3 \mathrm{~h}$ or $6 \mathrm{~h}$ before BrdU administration, respectively. Taken together, NT3 could alter the final destination of newly generated neurons in the cerebral cortex only when their parent progenitors were exposed to NT3 in the G1-phase.

Next, we evaluated the total number and the laminar distribution of cells $\mathrm{s}^{\mathrm{BrdU}+}$, in relation to the timing of NT3 injections. We observed that NT3 increased the number of cells ${ }^{\mathrm{BrdU}+}$ in the P6 cerebral cortex when NT3 was administered at $3 \mathrm{~h}$, but not $6 \mathrm{~h}$ before BrdU injection on E13.5 (Fig. 1E). These results indicate that NT3 increased the number of newly generated neurons, and altered their laminar distribution depending on the cell cycle of their parent progenitor cells.

NT3 influenced the laminar-specific expression of transcription factors in the cortical neurons through MEK/ERK1/2 signaling pathway

Next, we examined whether NT3 could influence on the cortical neurons in expression profiles of transcription factors. Each layer specifically expresses particular transcription factors such as Brn1 (layers II-III, V (21)), Cux1 (layers II-IV; (23)), Ctip2 (layer V; (3)), Tbr1 (layers III and V-VI; (14)), and Foxp2 (layer VI; (6)). The expression profiles of these transcription factors in each cortical layer were similar, irrespective of the NT3 treatment, and there was no difference in the number of cells expressing specific transcription factors among layers (Table 1, see overview in Fig. 2). Thus, NT3 caused no obvious abnormality in the pattern of the cortical lamination. In addition, there were no changes in the number of cells (stained with propidium iodide) in each sector, or in the total number of cells $\mathrm{s}^{\mathrm{BrdU}+}$ in layers I-VI (data not shown). Many cells ${ }^{\mathrm{BrdU}+}$ expressed Brn1 or Cux1, and others expressed Tbr1, but few cells ${ }^{\mathrm{BrdU}+}$ expressed Ctip2 or Foxp2 in the vehicle-treated cortex (Table 2, see overview in Fig. 2). In contrast, cells ${ }^{\mathrm{BrdU}+}$ expressing Brn 1 or Cux1 in NT3-treated mice were significantly increased in number, whereas cells ${ }^{\mathrm{BrdU}+}$ expressing Ctip2, Tbr1, or Foxp2 were significantly decreased in number (Table 2, see overview in Fig. 2). These data demonstrate that cells $\mathrm{s}^{\mathrm{Brd}+}$ that migrated ectopically to the upper cortical layers in response to NT3 treatment gained transcription factor-expression properties that corresponded to the upper cortical layers where they migrated to. Thus, NT3 regulated the laminar fate of newly generated neurons from the neural progenitors.

Previously, we demonstrated that NT3 facilitates ERK1/2 phosphorylation in VZ/SVZ cells within 2 $\mathrm{h}$ of administration, and the NT3-induced neurogenesis was diminished by co-administration of the mitogen-activated protein/extracellular signal-regulated kinase kinase (MEK) inhibitor with NT3 (25). Therefore, we examined whether the MEK/ERK1/2 signaling pathway participated in the NT3-induced changes in the laminar fate using the MEK inhibitor U0126. Animal experiments that investigated the effect of U0126 on corticogenesis in postnatal stages are difficult to evaluate because the animals typically do not survive more than 2 days after U0126 injection. This poor survivability likely indicates the necessity of MEKs for the survival of mouse embryos. Thus, we investigated NT3 actions on the laminar fate in cortical progenitors using primary cultures. Six hours after plating, BrdU was added in the medium, which was followed $6 \mathrm{~h}$ later with NT3 treatment, and then culturing for 7 days before fixation. Compared with controls, NT3 significantly increased the ratio of the cells ${ }^{\mathrm{BrdU}+}$ expressing the upper-layer marker (Cux1), and decreased the ratio of those expressing the deeper-layer marker (Tle4)

Table 1 Number of cells expressing layer-specific genes

\begin{tabular}{lccccc}
\hline & Brn1 $^{+}$ & Cux1 $^{+}$ & Ctip2 $^{+}$ & Tbr1 $^{+}$ & Foxp2 $^{+}$ \\
\hline lyII-IV & lyII-IV & lyV & lyV-VI & lyVI \\
\hline Control & $432.3 \pm 8.0$ & $449.0 \pm 13.7$ & $84.7 \pm 4.3$ & $419.8 \pm 24.0$ & $218.4 \pm 3.8$ \\
NT3 & $407.9 \pm 23.8$ & $470.7 \pm 30.9$ & $105.9 \pm 10.9$ & $455.8 \pm 9.9$ & $234.2 \pm 8.5$ \\
\hline
\end{tabular}

ly: layer. The values were expressed as the mean $\pm \operatorname{SE}(n=4)$. No significance (Student's $t$-test) 

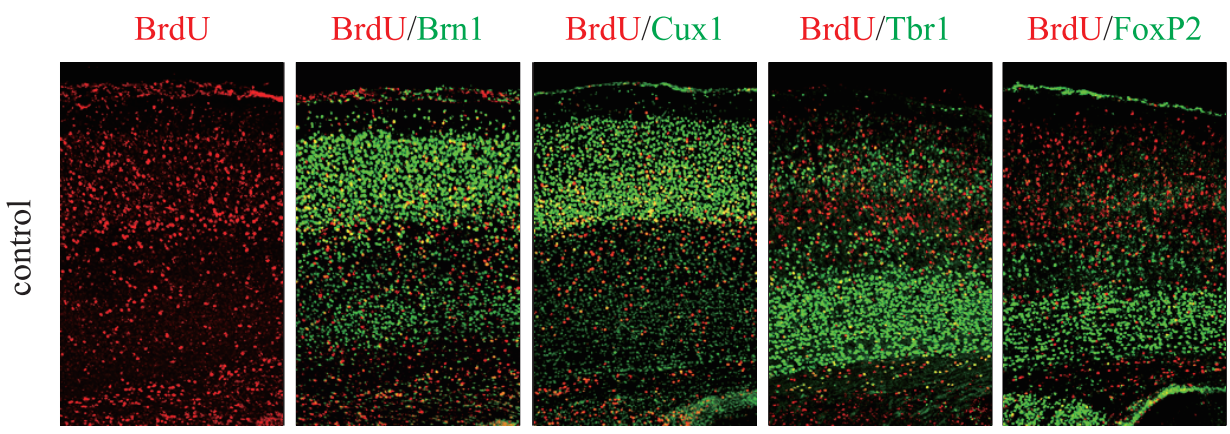

PI
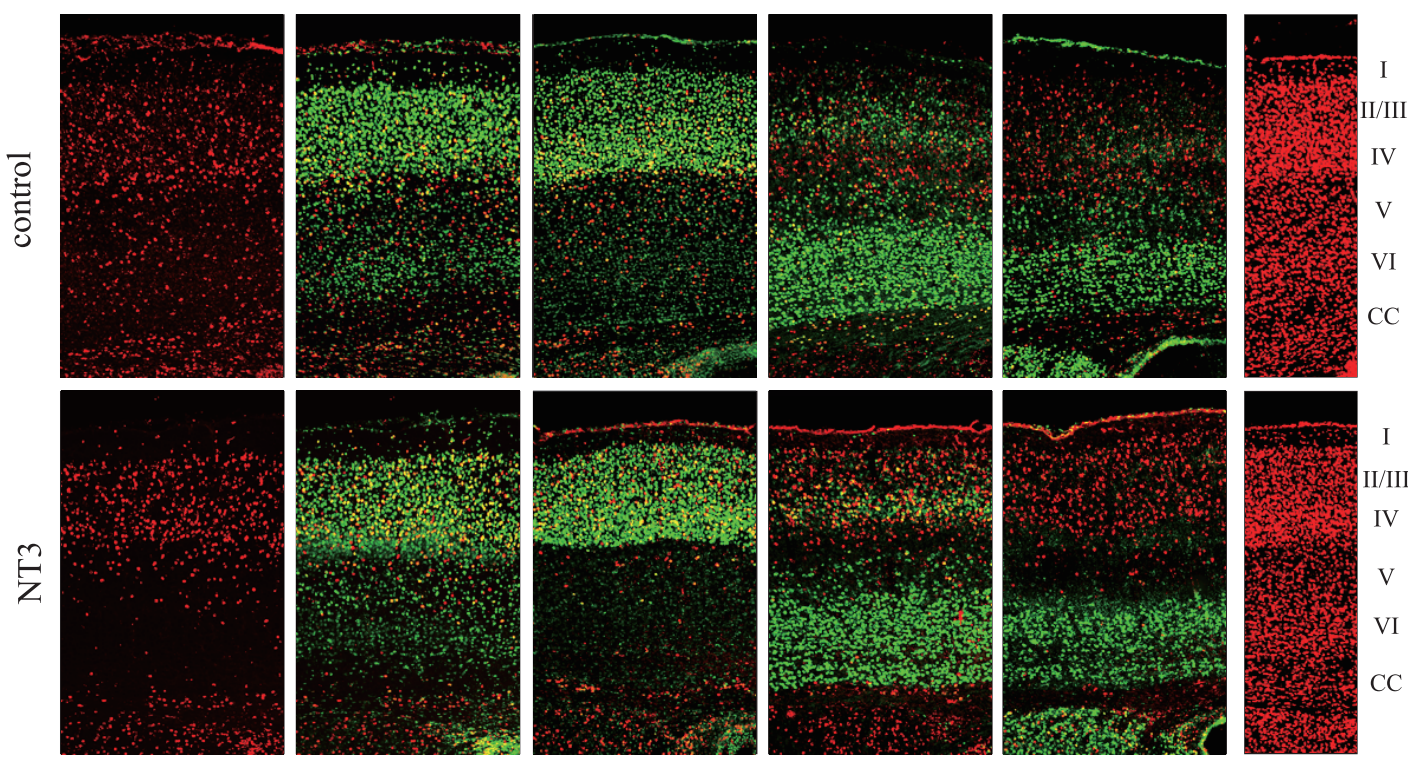

Fig. 2 NT3 altered the laminar-specific expression properties of transcription factors in the cortical neurons. The images show the distribution of cells that incorporated BrdU $6 \mathrm{~h}$ before NT3 injection in the P6 control cerebral cortex or NT3-treated cortex. Tissue sections were double immunostained with an anti-BrdU antibody (red) and one of the antibodies against layer-specific markers (Brn1, Cux1, Tbr1, or Foxp2; green). Scale bar of $200 \mu \mathrm{m}$.

Table 2 Effect of NT3 on the laminar fate of the BrdU-positive cells

\begin{tabular}{llllll}
\hline & \multicolumn{5}{c}{ Ratio of positive cells/total BrdU positive cells (\%) } \\
\cline { 2 - 5 } Control & Brn1 $^{+}$ & Cux 1 $^{+}$ & Ctip2 $^{+}$ & Tbr1 $^{+}$ & Foxp2 $^{+}$ \\
\hline NT3 & $27.9 \pm 1.7$ & $41.0 \pm 1.3$ & $4.6 \pm 0.6$ & $16.9 \pm 1.2$ & $3.5 \pm 0.2$ \\
\hline & $53.4 \pm 1.7^{* * *}$ & $51.4 \pm 0.6^{* * *}$ & $2.7 \pm 0.2^{*}$ & $2.8 \pm 0.3^{* * *}$ & $1.8 \pm 0.3^{* *}$ \\
\hline
\end{tabular}

Values are mean $\pm \mathrm{SE}(\mathrm{n}=4) .{ }^{*} P<0.05, * * P<0.01, * * * P<0.001$, respectively, Student's $t$-test.

(Fig. 3). These effects were abolished by pre-incubation of U0126 (Fig. 3), but not LY294002 (the PI3K inhibitor, data not shown). These results suggest that NT3 can influence the laminar-specific properties of cortical neurons through the MEK/ERK1/2 signaling pathway.

NT3 altered cyclin D1 and D2 expression in the developing cerebral cortex

G1 represents a critical phase during cell-cycle progression where cortical progenitors are competent to respond to extracellular cues that influence commitment of cell in further cell division or withdrawal from the cell cycle and affect embarking a differentiation pathway. The progression through the G1phase is driven by the sequential kinase activity of cyclin D/cdk4 and cyclin E/cdk2. Cyclin D1 and D2 are rate limiting for $\mathrm{G} 1 / \mathrm{S}$-transition. To test the possible involvement of these G1-phase regulators in NT3 actions, we examined the expression of cyclin
D1 and D2 after NT3 treatment. The expression of cyclin D1 and D2 was significantly increased $2 \mathrm{~h}$ after NT3 injection, but decreased to original levels 4-6 h after injection (Fig. 4). Thus, transient but significant upregulation of cyclin D1 and D2 expression induced by NT3 could affect the properties of cortical progenitors generating daughter neurons.

\section{DISCUSSION}

The present study revealed for the first time that NT3 is a putative environmental factor that influences both the number and the laminar specification of newly generated neurons during corticogenesis. NT3 increased the number of neurons when the parent progenitors were in the G1/S cell cycle phase, but altered the laminar-specific properties of daughter neurons when the parent progenitors were exposed in the G1-phase (Fig. 1). Both NT3 actions on the cortical progenitors were completely suppressed by 
A

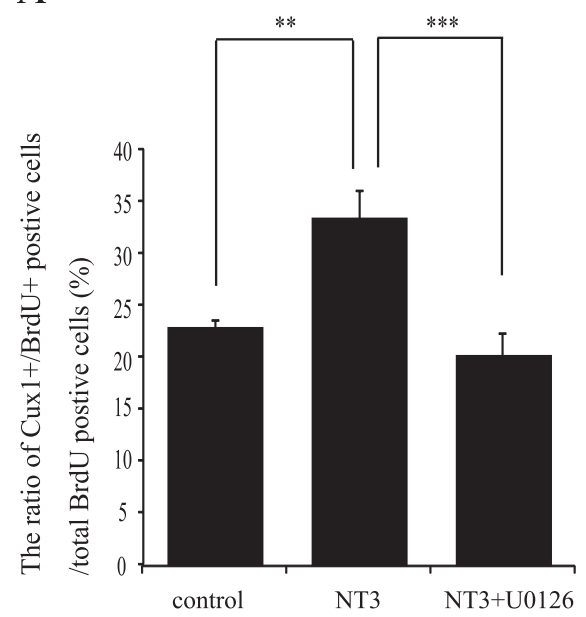

B

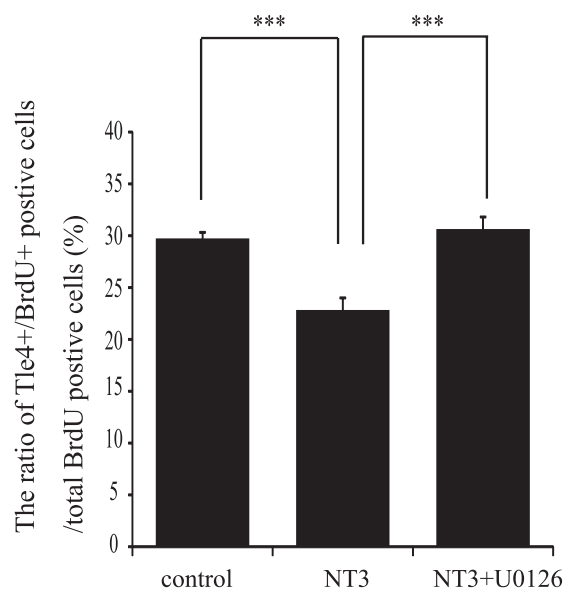

Fig. 3 Effect of the MEK inhibitor on the NT3-altered layer-specific gene expression properties of cultured cortical neurons. BrdU was added in the culture medium $6 \mathrm{~h}$ after the NT3 and/or MEK inhibitor (U0126) treatment, and the cells were cultured for 7 days before fixation. The number of cells ${ }^{\text {BrdU+ }}$ immunostained with Cux1 (A) or Tle4 (B) was expressed as a percentage of the total number of cells ${ }^{\mathrm{BrdU}+}$ (ANOVA, Tukey's post hoc test, ${ }^{* *} P<0.01,{ }^{* * *} P<0.001$ ).

A

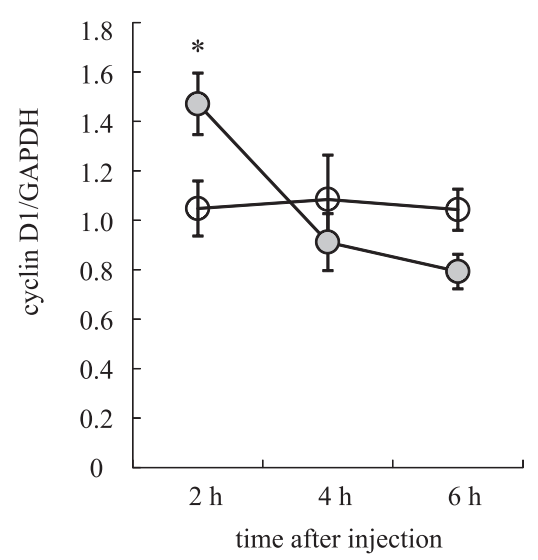

B

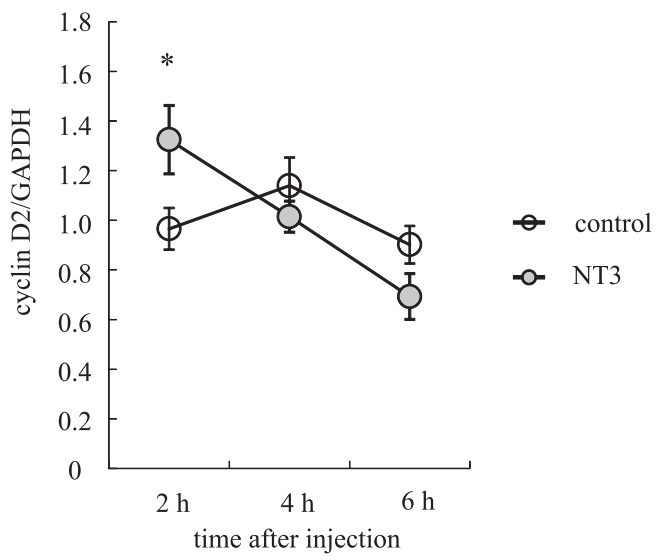

Fig. 4 NT3 transiently induced expression of cyclin D1 and D2 mRNAs. Total RNA was prepared from the cerebral cortex at the times indicated after NT3 administration, and was analyzed with quantitative RT-PCR using primers specific for cyclin D1, D2, and GAPDH. The mRNA levels of cyclin D1 and D2 are expressed as concentrations relative to GAPDH mRNA. Values are expressed as means \pm SE. Significant differences from the corresponding control (without NT3 treatment) were determined by ANOVA with Dunnett's post hoc test $\left({ }^{*} P<0.05, \mathrm{n}=8-16\right)$.

the MEK inhibitors (Fig. 3) (25). Considering that NT3 stimulates rapid and transient phosphorylation of ERK1/2 in progenitor cells (25), these results indicate that NT3 affects neurogenesis in two distinct ways: through cell-cycle dependent mechanisms and through the MEK/ERK1/2 pathway.

How can NT3 control these two distinct actions through the same MEK/ERK1/2 kinase signaling cascade? We found that cyclin D1 and D2 expressions were transiently increased within $2 \mathrm{~h}$ of NT3 administration (Fig. 4). In fibroblasts, cyclin Ds are key target molecules of the ERK1/2 MAP kinase pathway (22). Over expression of cyclin D1 in the cortical progenitors leads to the shortened G1-phase and increases the number of the progenitors and those of the daughter neurons with upper layer properties (18). Therefore, transient activation of MEK/ ERK1/2/cyclin D induced by NT3 might mediate its two distinct effects on cortical progenitor cells separately. Otherwise, these effects are sequential and inseparable. Similarly, MEK/ERK1/2 activation in fibroblasts is necessary for G1-phase progression 
(22); the activation must be sustained until the late G1-phase for the successful S-phase entry, whereas transient activation is insufficient (32).

During mouse corticogenesis, a progressive increase in neuron production rate is accompanied by an increase in the frequency of neurogenetic divisions, and elongation in the G1-phase of cortical progenitors (18). Recent studies have revealed that key cell cycle regulators control the expansion versus differentiation of the neural progenitors (4). Until now, only a few factors have been identified as environmental factors that can influence cortical progenitors with the laminar-specific properties. Some classes of neurotrophic factors and growth factors are strong candidates for such environmental factors $(8,24)$. These environmental factors exist in the SVZ/VZ and can control the expression and function of key cell cycle regulators in cortical progenitors. Progenitor cells in the early G1- or the late G1/S-phase transition may integrate signaling information from these neurotrophic factors, which determines the number and/or phenotypes of the daughter neurons.

\section{Acknowledgments}

This work was supported, in part, by Grants-in-Aid for Young Scientists (B) from Japan Society for the Promotion of Science (to H.F.). The authors would like to thank Enago (www.enago.jp) for the English language review.

\section{REFERENCES}

1. Angevine JB, Jr. and Sidman RL (1961) Autoradiographic study of cell migration during histogenesis of cerebral cortex in the mouse. Nature 192, 766-768.

2. Caviness VS, Jr. (1982) Neocortical histogenesis in normal and reeler mice: a developmental study based upon $\left[{ }^{3} \mathrm{H}\right]$ thymidine autoradiography. Brain Res 256, 293-302.

3. Chen B, Schaevitz LR and McConnell SK (2005) Fezl regulates the differentiation and axon targeting of layer 5 subcortical projection neurons in cerebral cortex. Proc Natl Acad Sci USA 102, 17184-17189.

4. Dehay C and Kennedy H (2007) Cell-cycle control and cortical development. Nature Rev Neurosci 8, 438-450.

5. Dominguez MH, Ayoub AE and Rakic P (2012) POU-III Transcription Factors (Brn1, Brn2, and Oct6) influence neurogenesis, molecular identity, and migratory destination of upper-layer cells of the cerebral cortex. Cereb Cortex [Epub ahead of print]

6. Ferland RJ, Cherry TJ, Preware PO, Morrisey EE and Walsh CA (2003) Characterization of Foxp2 and Foxp1 mRNA and protein in the developing and mature brain. J Comp Neurol 460, 266-279.

7. Fukumitsu H, Soumiya H and Furukawa S (2012) Knockdown of pre-mRNA cleavage factor Im $25 \mathrm{kDa}$ promotes neu- rite outgrowth. Biochem Biophys Res Commun 425, 848-853.

8. Fukumitsu H, Ohtsuka M, Murai R, Nakamura H, Itoh $\mathrm{K}$ and Furukawa S (2006) Brain-derived neurotrophic factor participates in determination of neuronal laminar fate in the developing mouse cerebral cortex. $J$ Neurosci 26, 13218-13230.

9. Fukumitsu H, Furukawa Y, Tsusaka M, Kinukawa H, Nitta A, Nomoto H, Mima T and Furukawa S (1998) Simultaneous expression of brain-derived neurotrophic factor and neurotrophin-3 in Cajal-Retzius, subplate and ventricular progenitor cells during early development stages of the rat cerebral cortex. Neuroscience 84, 115-127.

10. Gilbert CD and Kelly JP (1975) The projections of cells in different layers of the cat's visual cortex. J Comp Neurol 163, 81-105.

11. Gilbert CD and Wiesel TN (1985) Intrinsic connectivity and receptive field properties in visual cortex. Vision Res 25, 365-374.

12. Glickstein SB, Alexander S and Ross ME (2007) Differences in cyclin D2 and D1 protein expression distinguish forebrain progenitor subsets. Cereb Cortex 17, 632-642.

13. Hevner RF, Daza RA, Englund C, Kohtz J and Fink A (2004) Postnatal shifts of interneuron position in the neocortex of normal and reeler mice: evidence for inward radial migration. Neuroscience 124, 605-618.

14. Hevner RF, Shi L, Justice N, Hsueh Y, Sheng M, Smiga S, Bulfone A, Goffinet AM, Campagnoni AT and Rubenstein JL (2001) Tbr1 regulates differentiation of the preplate and layer 6. Neuron 29, 353-366.

15. Ito H, Nakajima A, Nomoto H and Furukawa S (2003) Neurotrophins facilitate neuronal differentiation of cultured neural stem cells via induction of mRNA expression of basic helix-loop-helix transcription factors Mash1 and Math1. $J$ Neurosci Res 71, 648-658.

16. Jin L, Hu X and Feng L (2005) NT3 inhibits FGF2-induced neural progenitor cell proliferation via the PI3K/GSK3 pathway. J Neurochem 93, 1251-1261.

17. Lamballe F, Smeyne RJ and Barbacid M (1994) Developmental expression of trkC, the neurotrophin-3 receptor, in the mammalian nervous system. J Neurosci 14, 14-28.

18. Lange C, Huttner WB and Calegari F (2009) Cdk4/cyclinD1 overexpression in neural stem cells shortens G1, delays neurogenesis, and promotes the generation and expansion of basal progenitors. Cell Stem Cell 5, 320-331.

19. Lukaszewicz A, Savatier P, Cortay V, Kennedy H and Dehay C (2002) Contrasting effects of basic fibroblast growth factor and neurotrophin 3 on cell cycle kinetics of mouse cortical stem cells. J Neurosci 22, 6610-6622.

20. McConnell SK and Kaznowski CE (1991) Cell cycle dependence of laminar determination in developing neocortex. Science 254, 282-285.

21. McEvilly RJ, de Diaz MO, Schonemann MD, Hooshmand F and Rosenfeld MG (2002) Transcriptional regulation of cortical neuron migration by POU domain factors. Science 295, $1528-1532$

22. Meloche S and Pouyssegur J (2007) The ERK1/2 mitogenactivated protein kinase pathway as a master regulator of the G1- to S-phase transition. Oncogene 26, 3227-3239.

23. Nieto M, Monuki ES, Tang H, Imitola J, Haubst N, Khoury SJ, Cunningham J, Gotz M and Walsh CA (2004) Expression of Cux-1 and Cux-2 in the subventricular zone and upper layers II-IV of the cerebral cortex. J Comp Neurol 479, 168180.

24. Ohtsuka M, Fukumitsu H and Furukawa S (2008) PACAP decides neuronal laminar fate via PKA signaling in the de- 
veloping cerebral cortex. Biochem Biophys Res Commun 369, 1144-1149.

25. Ohtsuka M, Fukumitsu H and Furukawa S (2009) Neurotrophin-3 stimulates neurogenetic proliferation via the extracellular signal-regulated kinase pathway. $J$ Neurosci Res 87, 301-306.

26. Paxinos G, Halliday G, Watoson C, Koutcherov $Y$ and Wang H (2007) Atlas of the Developing Mouse Brain at E17.5, P0, P6. Academic Press, San Diego.

27. Pilaz LJ, Patti D, Marcy G, Ollier E, Pfister S, Douglas RJ, Betizeau M, Gautier E, Cortay V, Doerflinger N, Kennedy H and Dehay C (2009) Forced G1-phase reduction alters mode of division, neuron number, and laminar phenotype in the cerebral cortex. Proc Natl Acad Sci USA 106, 21924-21929.

28. Pucilowska J, Puzerey PA, Karlo JC, Galan RF and Landreth GE (2012) Disrupted ERK signaling during cortical development leads to abnormal progenitor proliferation, neuronal and network excitability and behavior, modeling human neurocardio-facial-cutaneous and related syndromes. J Neurosci 32, 8663-8677.

29. Rakic P (1974) Neurons in rhesus monkey visual cortex: systematic relation between time of origin and eventual disposition. Science 183, 425-427.

30. Salomoni P and Calegari F (2010) Cell cycle control of mammalian neural stem cells: putting a speed limit on G1. Trends Cell Biol 20, 233-243.

31. Takahashi T, Nowakowski RS and Caviness VS, Jr. (1995) The cell cycle of the pseudostratified ventricular epithelium of the embryonic murine cerebral wall. $J$ Neurosci 15, 60466057.

32. Yamamoto T, Ebisuya M, Ashida F, Okamoto K, Yonehara S and Nishida E (2006) Continuous ERK activation downregulates antiproliferative genes throughout G1 phase to allow cell-cycle progression. Curr Biol 16, 1171-1182. 